\title{
Application of Broccoli Leaf Powder in Gluten-Free Bread: An Innovative Approach to Improve Its Bioactive Potential and Technological Quality
}

\author{
Urszula Krupa-Kozak *(D), Natalia Drabińska (D), Natalia Bączek, Kristýna Šimková, Małgorzata Starowicz (D) \\ and Tomasz Jeliński
}

check for

updates

Citation: Krupa-Kozak, U.;

Drabińska, N.; Bączek, N.; Šimková,

K.; Starowicz, M.; Jeliński, T.

Application of Broccoli Leaf Powder

in Gluten-Free Bread: An Innovative Approach to Improve Its Bioactive Potential and Technological Quality. Foods 2021, 10, 819. https://doi.org/ 10.3390 /foods10040819

Academic Editors: Alessandra Del Caro and Costantino Fadda

Received: 5 March 2021

Accepted: 6 April 2021

Published: 9 April 2021

Publisher's Note: MDPI stays neutral with regard to jurisdictional claims in published maps and institutional affiliations.

Copyright: (c) 2021 by the authors. Licensee MDPI, Basel, Switzerland. This article is an open access article distributed under the terms and conditions of the Creative Commons Attribution (CC BY) license (https:/ / creativecommons.org/licenses/by/ $4.0 /)$.
Institute of Animal Reproduction and Food Research, Polish Academy of Sciences, Tuwima 10 Str., 10-748 Olsztyn, Poland; n.drabinska@pan.olsztyn.pl (N.D.); n.baczek@pan.olsztyn.pl (N.B.); simkova.kris@gmail.com (K.Š.); m.starowicz@pan.olsztyn.pl (M.S.); t.jelinski@pan.olsztyn.pl (T.J.)

* Correspondence: u.krupa-kozak@pan.olsztyn.pl; Tel.: +48-89-523-46-18; Fax: +48-89-524-01-24
Abstract: In comparison to conventional bread, gluten-free bread (GF) shows many post-baking defects and a lower nutritional and functional value. Although broccoli leaves are perceived as waste products, they are characterised by a high content of nutrients and bioactive compounds. The present study evaluated the nutritional value, technological quality, antioxidant properties, and inhibitory activity against the formation of advanced glycation end-products (AGEs) of GF enriched with broccoli leaf powder (BLP). Compared to the control, gluten-free bread with BLP (GFB) was characterised by a significantly $(p<0.05)$ higher content of nutrients (proteins and minerals), as well as improved specific volume and bake loss. However, what needs to be emphasised is that BLP significantly $(p<0.05)$ improved the antioxidant potential and anti-AGE activity of GFB. The obtained results indicate that BLP can be successfully used as a component of gluten-free baked products. In conclusion, the newly developed GFB with improved technological and functional properties is an added-value bakery product that could provide health benefits to subjects on a gluten-free diet.

Keywords: Brassica; vegetable by-product; technological properties; texture parameters; antioxidant activity; anti-ages; gluten-free diet; coeliac disease

\section{Introduction}

Bread is a staple food that is willingly consumed all over the world every day [1]. However, for some individuals suffering from celiac disease and other gluten-related disorders (wheat allergy and non-celiac gluten sensitivity), the consumption of conventional wheat bread and other gluten-containing products is harmful [2]. In those patients, the dietary gluten proteins or, specifically, the gliadin fraction of wheat and the prolamins from barley (hordeins) and rye (secalins) can lead to deleterious health risks and complications. Nowadays, the only available treatment for gluten-related disorders is adherence to a gluten-free diet.

Gluten-free breadmaking is a process that varies substantially from conventional breadmaking - in particular, in the ingredients used, batter rheological behaviour, and overall quality of the final product [3]. Due to the absence of the continuous three-dimensional gluten network that is responsible for the rheological properties of the dough and the development of high-quality bread, gluten-free breadmaking is challenging [4]. Therefore, the production of gluten-free bread (GF) requires complex formulations, consisting of a mixture of non-gluten basic ingredients and various additives mimicking the viscoelastic properties of gluten [5], as well as diverse technological solutions. In comparison with conventional bread, a GF shows many post-baking defects, such as unattractive appearance (irregular crust surface and pale colour), poor mouthfeel and flavour, and a shorter shelflife. Over the last decade, considerable advances were made to improve the technological 
and sensory quality of GF and to prolong its shelf-life [6]. However, recently, a growing number of consumers are interesting in gluten-free products characterised by improved nutritional and health-promoting quality.

Numerous studies have shown that the fruits and vegetables-based by-products contain a substantial amount of nutrients (proteins, vitamins, and minerals), as well as functional (dietary fibre) and bioactive compounds (carotenoids, phenolic compounds, and glucosinolates) [7]. Among them, phytochemicals evince important biological activities, such as antioxidant and antimicrobial properties, thus could play a role in the prevention and treatment of noncommunicable human diseases. The beneficial effects of polyphenols and the glucosinolate derivative towards the organism, including the prevention against civilisation diseases such as cardiovascular pathologies, type 2 diabetes, some types of cancer, and neurodegenerative diseases, were widely discussed in the literature [8-10]. For that reason, the increasing number of research focuses on the application of by-products in gluten-free products as low-cost sources of nutrients and bioactive compounds [11-13]. Recently, Littardi et al. [14] evaluated the impact of the addition of ground coffee parchment to GF and indicated that this by-product was able to improve the colour of this bakery product together with a significant enhancement in the antioxidant capacity and oxidative stability.

The Brassicaceae family includes many vegetables commonly consumed worldwide, not only traditionally for nutrition but, more importantly, for their health-promoting properties [15]. Among them, broccoli (Brassica oleracea var. italica) has acquired considerable relevance in the last few years as a "therapeutic" food, since it contains pharmacologically active substances [16,17]. Many studies have been focused on broccoli florets, which represent only $15 \%$ of the total aerial biomass [18]. While we were interested in broccoli by-products-in particular, leaves_that are seldom utilised for food. Broccoli leaves, similar to florets, are characterised by a high content of nutrients (proteins, vitamin C, minerals, and trace elements) and bioactive compounds (glucosinolates, phenolic acids, and flavonoids) $[19,20]$. Although perceived as a waste product, they might be consumed as a valuable fresh product or as sources of phytonutrients, allowing to obtain added-value baked products $[21,22]$. Thus, the valorisation of broccoli by-products and their application as the ingredient of gluten-free bakery products of potential nutraceutical properties could be one of the alternative strategies to reduce food waste $[23,24]$. The present study investigated the suitability and functionality of broccoli leaf powder (BLP) as a GF component based on an analysis of the nutritional value, technological quality, antioxidant properties, and inhibitory activity against the formation of advanced glycation end-products (AGEs) of the developed gluten-free bread enriched with BLP (GFB).

\section{Materials and Methods}

\subsection{Preparation of Broccoli Leaf Powder}

A BLP was prepared as described previously [24]. Briefly, undamaged leaves of mature broccoli (Brassica oleracea L. var. italica) donated by the company GEMIX (Olsztyn, Poland) were cleaned of soil residues, washed with water, then blanched shortly (1 min) in hot water to inactivate enzymes and decrease the microbial load. Afterward, petioles and main midribs were removed, and leaf blades were freeze-dried, since it is a method that preserves the nutritional and biological value and the colour of the raw material [25]. Dry leaves were ground and sieved to obtain homogenous powder (particle size $\leq 0.60 \mathrm{~mm}$ ). The obtained BLP was packed in a sealed plastic box and kept in a refrigerator for further analysis and application in experimental GF formulation.

\subsection{Preparation of Experimental Gluten-Free Bread}

In this study, an optimised GF formula [26] was used as a control (GFC). Corn starch (HORTIMEX, Konin, Poland), potato starch (PPZ “Trzemeszno” Sp. Z o.o., Trzemeszno, Poland), sugar, fresh yeast (Lesaffre Polska S.A., Wołczyn, Poland), pectin (E 440(i), ZPOW Pektowin, Jasło, Poland), rapeseed oil "Kujawski" (ZT “Kruszwica” S.A., Kruszwica, 
Poland), salt, and water were the main ingredients of GFC (Table 1). Previously characterised BLP [24] was incorporated into the GFB by replacing $5 \%(w / w)$ of corn starch in the GFC formula. This level of substitution was based on a preliminary study that showed that $5 \%$ was the acceptable replacement level that did not affect the sensory properties of bread, whereas the GFB with 7\% BLP had too intense cabbage flavour (data not shown).

Table 1. Composition of experimental gluten-free bread.

\begin{tabular}{ccc}
\hline Ingredient (\%) & GFC & GFB \\
\hline Corn starch & 36.7 & 31.7 \\
Potato starch & 8.9 & 8.9 \\
Pectin & 2.2 & 2.2 \\
Sugar & 2.8 & 2.8 \\
Salt & 0.8 & 0.8 \\
Oil & 1.4 & 1.4 \\
Fresh yeast & 2.8 & 2.8 \\
BLP & - & 5 \\
Water & 44.4 & 44.4 \\
\hline
\end{tabular}

GFC-Control gluten-free bread, GFB-Gluten-free bread enriched with broccoli leaf powder, and BLP—Broccoli leaf powder.

To prepare GFs, all solid ingredients were mixed for $5 \mathrm{~min}$ at minimum speed using a KitchenAid Professional K45SS mixer (KitchenAid Europa, Inc, Brussels, Belgium) in the stainless-steel bowl with a flat beater. Yeast, salt, and sugar were dissolved in the water and added to the dry mixture, together with oil. The batter was mixed for $12 \mathrm{~min}$ at speed 2. Then, a 240-g sample of the resulting batter was placed in a greased hexagon-shaped bread pan $(10 \mathrm{~cm} \times 10 \mathrm{~cm} \times 9 \mathrm{~cm}$ length, width, and height, respectively) and proof for $40 \mathrm{~min}$ at $35^{\circ} \mathrm{C}$ and $70 \%$ humidity. Experimental GFs were baked for $30 \mathrm{~min}$ at $220{ }^{\circ} \mathrm{C}$ in the laboratory oven (AB model DC-21, SVEBA DAHLEN, Fristad, Sweden). Nine loaves were baked from each formula. After baking, all bread loaves were cooled for at least $2 \mathrm{~h}$ at room temperature. Then, GFs were packed in clip-on plastic bags and kept in the dark at room temperature for further analysis. Products of two independent batches, fresh $(2 \mathrm{~h}$ after baking) and/or stored ( 24 and $72 \mathrm{~h}$ after baking), were analysed.

\subsection{Characteristics of Experimental Gluten-Free Breads}

\subsubsection{Determination of Proximal Chemical Composition and Energy Value}

The basic chemical composition was determined in freeze-dried GFs according to the standard method [27]: moisture content was analysed using the drying method (AOAC 925.10), proteins content was determined with the Kjeldahl method $(\mathrm{N} \times 6.25$ for nitrogen to protein conversion) (AOAC 979.09), and fat content using Soxhlet extraction with hexane (AOAC 923.03); total ash was determined using the gravimetric method by burning in a muffle furnace at $550{ }^{\circ} \mathrm{C}$ for $10 \mathrm{~h}$ (AOAC 923.03). The total carbohydrate content was calculated by subtracting the values of the moisture, protein, fat, and ash content from 100 . The energy values $(\mathrm{kJ})$ were calculated by multiplying the amount of macronutrients by the corresponding conversion factors $(17 \mathrm{~kJ} / \mathrm{g}$ for protein, $37 \mathrm{~kJ} / \mathrm{g}$ for fat, and $17 \mathrm{~kJ} / \mathrm{g}$ for carbohydrates) [28]. The conversion factor for calories calculation is $1 \mathrm{~kJ}=0.239 \mathrm{kcal}$.

\subsubsection{Determination of Physical Parameters}

The weight of GFs was evaluated using a digital balance with 0.01-g accuracy. The loaf volume was determined using a modified standard rapeseed displacement method, in which millet seeds were used instead of rapeseed. The specific volume (SV) was calculated as a loaf volume divided by its weight. Density (D) was calculated as a loaf weight divided by its volume. Bake loss was calculated as indicated in Equation (1).

$$
\text { Bake loss }(\%)=\frac{(a-b) \times 100}{a}
$$


where:

$a$ - the initial weight of batter before baking $(\mathrm{g})$, and

$b$ - the weight of baked and cooled GFs (g).

The crust and crumb colour of GFs was evaluated using a HunterLab ColorFlex (Hunter Associates Laboratory, Inc, Reston, VA, USA). Crust colour was determined at the middle point of the top of the loaf crust, while crumb colour was analysed at the middle point of the central 2-cm slice. The measurements were performed through a $3-\mathrm{cm}$ diameter diaphragm containing an optical glass. The colour was expressed in accordance with the CIELab system, and the parameters determined were: lightness ( $L^{*}=0$ (black) and $L^{*}=100$ (white) and chromatic components: $a^{*}\left(-a^{*}=\right.$ greenness and $+a^{*}=$ redness) and $b^{*}$ $\left(-b^{*}=\right.$ blueness and $+b^{*}=$ yellowness). Values were the mean of at least nine replicates.

To present the appearance of crumb and crust of exemplary GFC and GFB scans of the example central slice of each experimental, GF was made using a flatbed scanner (Epson Perfection V200 Photo) supported by Epson Creativity Suite Software Images (Figure 1).

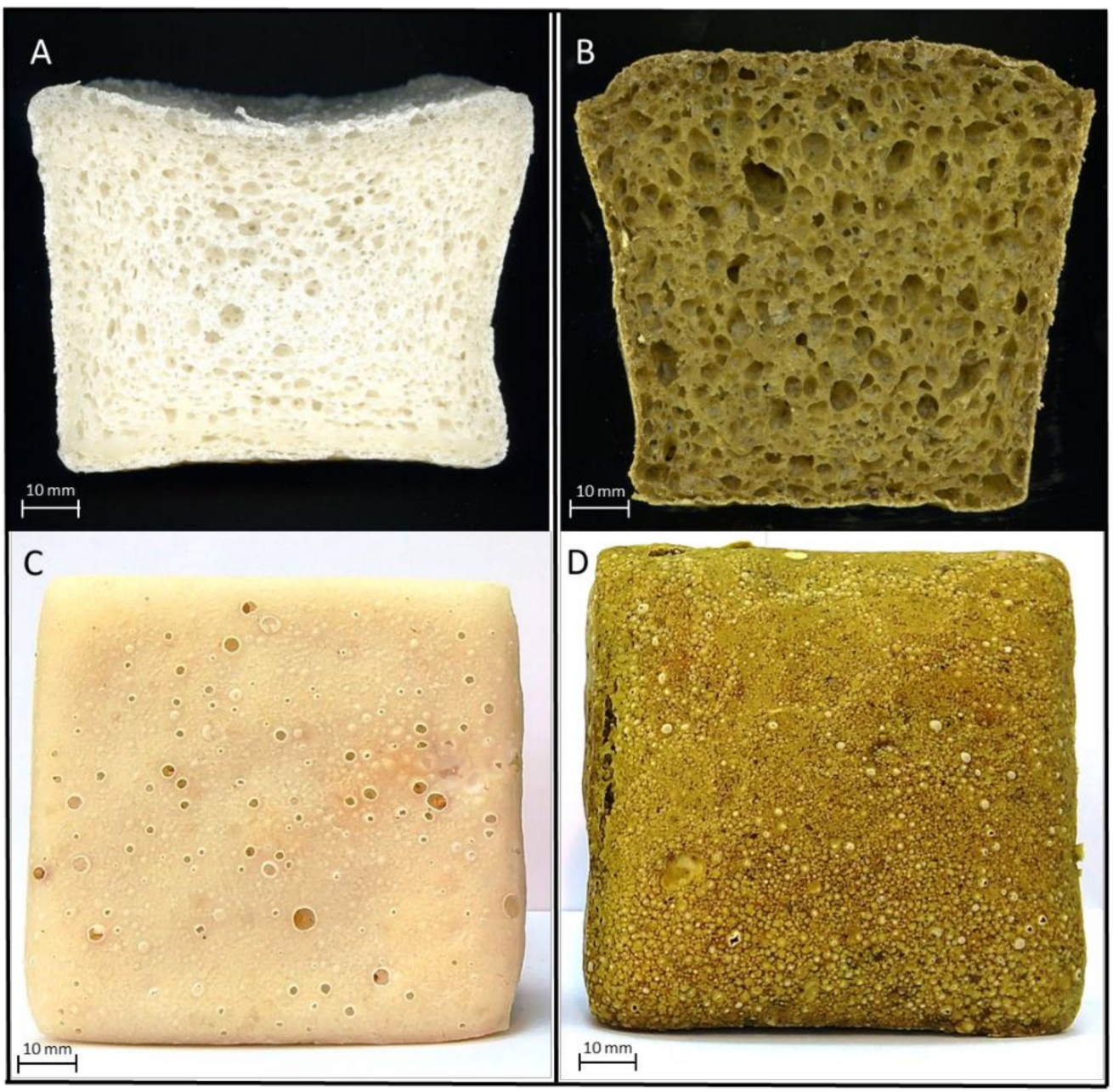

Figure 1. The visual appearance of crumb and crust of exemplary control gluten-free bread $(\mathbf{A}, \mathbf{C})$ and gluten-free bread with broccoli leaves powder $(\mathbf{B}, \mathbf{D})$.

\subsubsection{Evaluation of Textural Properties}

The texture profile (TPA test) of fresh ( $2 \mathrm{~h}$ ) and stored (for 24 and $72 \mathrm{~h}$ after baking) crumbs of GFs were analysed using a TA.HD Plus Texture Analyser (Stable Micro Systems Ltd., Godalming, UK) equipped with a 30-kg load cell. The middle bread slices of $25-\mathrm{mm}$ thickness underwent a double compression cycle up to $40 \%$ deformation of its original height with a 35-mm flat-end aluminium compression disc (probe P/35). The selected 
settings were as follows: pre-test/test/post-test speed, $2.0 \mathrm{~mm} / \mathrm{s}$, relaxation time, $5 \mathrm{~s}$, force, $10 \mathrm{~g}$, and trigger, mode auto. Each slice was compressed twice to give a two-bite texture profile curve [29], from which the following textural parameters were obtained: hardness, springiness, chewiness, cohesiveness, and resilience, as calculated by the software of the texturometer. Six replicates were analysed for each kind of fresh and stored GF.

\subsection{Evaluation of the Antioxidant Capacity of BLP and GFs}

\subsubsection{Determination of Total Phenolic Content}

The total phenolic content (TPC) was determined with the use of the Folin-Ciocalteu reagent based on the method described previously by Horszwald and Andlauer [30]. Methanol extracts were obtained from $200 \mathrm{mg}$ of freeze-dried GF and $100 \mathrm{mg}$ of BLP with 1 $\mathrm{mL}$ of $67 \%$ methanol. Samples were subjected to ultrasonic vibration (30 s) and vortexing (30 s), then were centrifuged for $10 \mathrm{~min}$ at $13,000 \mathrm{rpm}$ at $4{ }^{\circ} \mathrm{C}$. The above step was repeated five times, and the supernatants were collected into a 5-mL measuring flask. Methanol extracts were prepared in triplicate. The TPC assay was performed in microplates, and aliquots of $15 \mu \mathrm{L}$ of methanol extracts were placed in microplate wells. Subsequently, $250 \mu \mathrm{L}$ of the Folin-Ciocalteu reagent (previously diluted with water 1:15, $v / v$ ) was added, and the mixture was incubated for $10 \mathrm{~min}$ in dark at room temperature. Then, $25 \mu \mathrm{L}$ of $20 \%$ sodium carbonate was added to each well, and the mixture was incubated for $20 \mathrm{~min}$. The microplate was shaken automatically before reading, and absorbance was measured at $\lambda=755 \mathrm{~nm}$ with the Infinite M1000 PRO plate reader (Tecan Group AG, Männedorf, Switzerland). Gallic acid was used for standard calibration $\left(0.03-1.0 \mathrm{mg} \mathrm{L}^{-1}\right)$, and the results were expressed in $\mathrm{mg}$ of gallic acid equivalents (GAE) per one gram of dry matter (g DM) of GFs or BLP.

\subsubsection{Trolox Equivalent Antioxidant Capacity by ABTS Assay}

The Trolox Equivalent Antioxidant Capacity (TEAC) by the 2,2'-azino-bis(3-ethylbenzothiazoline-6-sulfonic acid (ABTS) assay was performed as described by Horszwald and Andlauer [30]. To obtain an ABTS radical cation (ABTS $\cdot^{+}$) solution with an absorbance value of $0.70 \pm 0.02$ at $734 \mathrm{~nm}, 10 \mathrm{~mL}$ of $7-\mathrm{mmoL} / \mathrm{L}$ aqueous solution of ABTS and $0.5 \mathrm{~mL}$ of 51.4-mmoL/ $\mathrm{L}^{-1}$ aqueous solution of $\mathrm{K}_{2} \mathrm{~S}_{2} \mathrm{O}_{4}$ were mixed, then stored in the dark at room temperature for $16 \mathrm{~h}$. Next, the ABTS. ${ }^{+}$solution $(1480 \mu \mathrm{L})$ was added to $20 \mu \mathrm{L}$ of methanol extracts of BLP and GF. For the analysis in the microplates, aliquots of $10 \mu \mathrm{L}$ of sample (the methanol extracts of BLP or GF prepared as described above for the TPC assay), standards, or blanks were placed in microplate wells. The reaction and time measurements were started upon the addition of $270 \mu \mathrm{L}$ of the ABTS. ${ }^{+}$solution. The reaction was carried out at $30{ }^{\circ} \mathrm{C}$ in dark for $6 \mathrm{~min}$. After the reaction, the absorbance was measured at $734 \mathrm{~nm}$ with a microplate reader. Trolox was used for standard calibrations $\left(0.25-1000 \mu \mathrm{mol} / \mathrm{L}^{-1}\right)$, and the results were expressed in $\mu$ mol Trolox $g^{-1}$ DM of GFs or BLP.

\subsubsection{Trolox Equivalent Antioxidant Capacity by DPPH Assay}

The TEAC by 2-diphenyl-picryl-hydrazyl (DPPH) radical scavenging assay was performed according to Horszwald and Andlauer [30]. To obtain the DPPH solution absorbing in the range from 0.95 to 1.10 at $\lambda=517 \mathrm{~nm}, 10 \mathrm{mg}$ of DPPH was dissolved in $250 \mathrm{~mL}$ of $80 \%$ methanol. The DPPH solution was freshly prepared before analysis. For analysis, $20 \mu \mathrm{L}$ of methanol extracts of BLP and GF (described in Section 2.4.1), blanks or standard were placed into microplate wells, and then, $300 \mu \mathrm{L}$ of DPPH. solution was added. The reaction was performed at ambient temperature for $30 \mathrm{~min}$ in the dark. Trolox was used for standard calibration $(0.005-0.75 \mathrm{mM})$, and results obtained were expressed as $\mu \mathrm{mol}$ Trolox Equivalents (TE) per $\mathrm{g}$ DM of GFs or BLP.

\subsubsection{Photochemiluminescence Assay}

A photochemiluminescence (PCL) assay was performed as described by Zieliński, Zielińska, and Kostyra [31]. This method was used to measure the antioxidant capacity of 
BLP and freeze-dried GF extracts against superoxide anion radicals generated from the luminol photosensitiser under exposure to UV light in the Photochem apparatus (Analytik Jena, Leipzig, Germany). Antioxidant activity was analysed with ACW (hydrophilic condition) and ACL (lipophilic condition) kits according to the manufacturer's protocols. For ACW, a 50-mg sample was extracted with $1 \mathrm{~mL}$ of water, and for ACL-a 50-mg sample was extracted with $1 \mathrm{~mL}$ of the $\mathrm{MeOH}$ and hexane mixture $(4: 1 ; v / v)$. The concentration of the extract solution was adjusted to ensure that the generated luminescence was within the range of the standard curve. Antioxidant capacity was calculated by comparing the delay time of the sample with the Trolox standard curve, and it was expressed in $\mu$ mol Trolox $\mathrm{g}^{-1} \mathrm{DM}$.

\subsection{Evaluation of Inhibiting Activity Against AGEs}

The inhibiting activity against advanced glycation end-products (AGEs) was assessed using two in vitro model systems: bovine serum albumine (BSA)-glucose and BSA-methylglyoxal (MGO). The extraction and incubation procedures were adopted from Szawara-Nowak et al. [32]. Briefly, $150 \mathrm{mg}$ of freeze-dried sample was extracted with $67 \%$ methanol by shaking at $25^{\circ} \mathrm{C}$ for 40 min using a thermomixer (Thermomixer, Eppendorf, Poland). The supernatant obtained after the centrifugation was evaporated to dryness under nitrogen, and the dry residue was dissolved in phosphate buffer $(0.1 \mathrm{M}, \mathrm{pH} 7.4)$. $0.5 \mathrm{~mL}$ of the obtained solution was incubated with $1 \mathrm{~mL}$ of the mixture containing BSA $(10 \mathrm{mg} / \mathrm{mL})$ and sodium azide $(0.1 \mathrm{mg} / \mathrm{mL})$ in phosphate buffer $(0.1 \mathrm{M}, \mathrm{pH} 7.4)$ and appropriately D-glucose or MGO. For the measurement, $250 \mu \mathrm{l}$ of the reaction mixture was placed into wells (microplate 96-wells, black, Porvair). The fluorescent intensity of $\lambda_{\text {excitation }} 330 \mathrm{~nm}$ and $\lambda_{\text {emission }} 410 \mathrm{~nm}$ (BSA-glucose), and $\lambda_{\text {excitation }} 340 \mathrm{~nm}$ and $\lambda_{\text {emission }}$ $420 \mathrm{~nm}$ (BSA-MGO) were measured. For each extract, the test was run in triplicate. A $1 \mathrm{mM}$ of aminoguanidine was used as a positive control. The results were presented as a percentage of AGEs inhibitory activity.

\subsection{Statistical Analysis}

Unless otherwise stated, the data reported in all the tables are mean values and standard deviations of triplicate observations. Generally, the differences between experimental GFs were analysed with an unpaired $t$-test with Weich's correction $(p<0.05)$, except for the differences between GFs caused by storage time that was analysed with the one-way ANOVA, using GraphPad Prism version 8.0.0 for Windows, GraphPad Software (San Diego, CA, USA).

\section{Results and Discussion}

\subsection{Proximal Chemical Composition and Energy Value of Experimental Gluten-Free Breads}

The BLP applied in the present study was previously characterised in terms of the proximal chemical composition and the profile of bioactive compounds [24] and was shown to be a good source of proteins. Additionally, a recent study by Sedlar et al. [7] indicated that, among the analysed vegetable byproducts, the broccoli leaves were characterised with the highest content of protein. In comparison with a GFC, the incorporation of BLP into the GFB resulted in a significant $(p<0.05)$ increase in the protein content (Table 2$)$; however, in practical terms, it was a relatively small increase $(1.16 \mathrm{~g} / 100 \mathrm{~g})$. Besides proteins, BLP was abundant in mineral compounds [24]; therefore, a significant $(p<0.05)$ enrichment in minerals was determined in experimental GFB, compared with GFC (Table 2). The obtained results are in agreement with the study by Ranawana et al. [33], who investigated the effect of the addition of the freeze-dried vegetable powder on the nutritional and physicochemical properties of wheat bread. The authors indicated that the addition of freeze-dried broccoli significantly $(p<0.05)$ increased the protein, fat, and total mineral contents in oil-free wheat bread. According to Betoret and Rosell [34], the particle size of vegetable powder affects significantly its physicochemical properties. The concentration of macronutrients (proteins and fat) in the powder of Brassica napobrassica leaves progressively 
increases as the particle size was reduced $(<125 \mu \mathrm{m})$; conversely, a fraction of larger particle size $(>1 \mathrm{~mm})$ was abundant in dietary fibre. Broccoli leaves used in the present study, after being freeze-dried and ground, were sieved to obtain a homogenous powder of average particle size below $0.60 \mathrm{~mm}$. Therefore, even if the physical properties of BLP could have an impact on the nutritional value of the enriched product, BLP could be recommended as an ingredient enriching GF in nutritional compounds, as similarly indicated by Sedlar et al. [7]. The energy value of GFB was higher than that of unsupplemented GFC (Table 2), mainly due to a higher fat content delivered by BLP [7]. Broccoli leaves are a rich source of polyunsaturated fatty acids, mainly $\alpha$-linolenic, linoleic, and palmitic acids $[35,36]$, which is their additional important nutritional benefit. However, the profile of fatty acids was not analysed in this study and requires further confirmation.

Table 2. Macronutrients content and energy value of experimental gluten-free bread.

\begin{tabular}{cccc}
\hline & GFC & GFB & $p$-Value \\
\hline Moisture & $55.67^{\mathrm{a}} \pm 0.18$ & $55.32^{\mathrm{a}} \pm 0.15$ & 0.0628 \\
Proteins & $1.22^{\mathrm{b}} \pm 0.04$ & $2.38^{\mathrm{a}} \pm 0.09$ & 0.0004 \\
Ash & $1.81^{\mathrm{b}} \pm 0.03$ & $2.16^{\mathrm{a}} \pm 0.04$ & 0.0004 \\
Fat & $0.87^{\mathrm{b}} \pm 0.01$ & $2.33^{\mathrm{a}} \pm 0.03$ & $<0.0001$ \\
Carbohydrates * & $40.56^{\mathrm{a}} \pm 0.15$ & $37.81^{\mathrm{b}} \pm 0.08$ & $<0.0001$ \\
Energy value (kJ) & $740^{\mathrm{b}} \pm 4$ & $769^{\mathrm{a}} \pm 2$ & 0.0060 \\
Energy value (kcal) & $177^{\mathrm{b}} \pm 1$ & $184^{\mathrm{a}} \pm 1$ & 0.0010 \\
\hline
\end{tabular}

${ }^{*}$ Calculated from the difference. GFC-Control gluten-free bread and GFB-Gluten-free bread enriched with broccoli leaf powder. Proximate macronutrients values are g per $100 \mathrm{~g}$ of dry matter. Within each row, and for each factor, values with the same letter do not differ significantly $(p<0.05)$ when subjected to the unpaired $t$-test with Weich's correction.

\subsection{Technological Parameters of Experimental Gluten-Free Bread}

The effect of BLP on the technological parameters of experimental GFs is shown in Table 3. Moreover, the differences in the appearance between the GFC and GFB can be perceived in Figure 1. The specific volume of the GFC determined in the present study was similar to the results reported previously [26]; however, in comparison with wheat bread, the value of this parameter was meaningfully lower [37]. A specific volume of a conventional wheat bread ranged from 3.5 to $5.5 \mathrm{~cm}^{3} / \mathrm{g}[38,39]$, while its value for GF was meaningfully reduced and fluctuated around $2 \mathrm{~cm}^{3} / \mathrm{g}$, depending on the ingredients used $[26,40]$. The use of BLP in the experimental GF formulation influenced the technological parameters of GFB. Compared with a GFC, the specific volume of GFB rose by approximately $30 \%$ (Table 3). Besides that, a significant decrease in the bake loss was detected in GFB. The specific volume is one of the most important technological parameters of bread quality; however, it cannot be considered as the most important quality factor itself. In breads baked in pans, high values of specific volume, usually associated with proper aeration of the bread loaves, are required to obtain products able to satisfy the consumers [41]. Therefore, the appropriate gas bubble entrapment together with stabilisation of the foam structure are also essential to achieve an acceptable texture, in which the resulting pores should be small, regular, and spread regularly across the crumb. On the other side, changes determined in both parameters could result from the BLP characteristics as physical parameters of bread depending on the type and amount of protein used in dough formulation, as well as on its interaction with starch. A recent study by Sedlar et al. [7] demonstrated that proteins obtained from broccoli leaves exhibited important functional properties, including a high solubility in the alkaline condition, favourable emulsifying abilities, and water absorption capacities, as well as foaming capacity and stability. Therefore, it is possible that BLP, due to high protein content, could influence the stability of the batter during baking. Consequently, it is possible that proteins of BLP could potentially form a stable network, somewhat mimicking gluten properties. However, the study by Ranawana et al. [33] showed contrary results, indicating that wheat bread with freeze-dried broccoli powder (10\%) exhibited a poor degree of leavening and was, therefore, 
the smallest, compared with loaves of bread with other vegetable powders. The authors explained the reduced volume of broccoli bread by the activity of enzymes present in the cruciferous vegetables [42]. Whilst in the present study, the BLP was prepared from thermally pretreated leaves (blanched). Thus, these enzymes were inactivated, creating optimal conditions for yeast fermentation that resulted in the improvement of the technological quality of GFB.

Table 3. Technological parameters of experimental gluten-free bread.

\begin{tabular}{cccc}
\hline & GFC & GFB & $p$ Value \\
\hline Specific volume (mL/g) & $2.41^{\mathrm{b}} \pm 0.14$ & $3.08^{\mathrm{a}} \pm 0.16$ & 0.0058 \\
Bake loss $(\%)$ & $14.96^{\mathrm{b}} \pm 0.09$ & $12.07^{\mathrm{a}} \pm 0.63$ & 0.0141 \\
Crust colour & & & \\
$L^{*}$ & $75.89^{\mathrm{a}} \pm 1.70$ & $50.41^{\mathrm{b}} \pm 1.52$ & $<0.001$ \\
$a^{*}$ & $1.58^{\mathrm{b}} \pm 0.08$ & $-3.65^{\mathrm{a}} \pm 0.31$ & $<0.001$ \\
$b^{*}$ & $17.28^{\mathrm{b}} \pm 1.12$ & $31.95^{\mathrm{a}} \pm 0.94$ & $<0.001$ \\
Crumb colour & $71.58^{\mathrm{a}} \pm 1.70$ & $34.92^{\mathrm{b}} \pm 2.81$ & $<0.001$ \\
$L^{*}$ & $0.35^{\mathrm{b}} \pm 0.11$ & $-1.47^{\mathrm{a}} \pm 0.14$ & $<0.001$ \\
$a^{*}$ & $11.15^{\mathrm{b}} \pm 0.73$ & $27.93^{\mathrm{a}} \pm 1.85$ & $<0.001$ \\
\hline$b^{*}$ & & & \\
\hline
\end{tabular}

FC-Control gluten-free bread, GFB-Gluten-free bread enriched with broccoli leaf powder, and BLP-Broccoli leaf powder. Within each row, and for each factor, values with the same letter do not differ significantly $(p<0.05)$ when subjected to the unpaired $t$-test with Weich's correction.

The results of the instrumental colour analysis of experimental GFs are presented in Table 3. The application of BLP influenced significantly $(p<0.05)$ all the analysed parameters of colour in the experimental bread. Both the crust and crumb of GFB were much darker (50.41 and 34.92, respectively) than the crust and crumb of GFC (75.89 and 71.58, respectively), which were pale and whitish. The crust and crumb colour strongly influence consumer choices [43]. Therefore, the darkening of starchy GFs is desirable and beneficial, as usually, they tended to have a light-coloured crust [26] that, in comparison with wheat flour counterparts, is perceived as unattractive. The visual colour difference between the typically creamy GFC and greenish-brown GFB (Figure 1) was evidenced by a colorimetric analysis. Contrary to the positive $a^{*}$ value indicating a slightly reddish colour of the GFC, a negative value of this coordinate was determined for the crust $(-3.65 \pm 0.31)$ and crumb $(-1.47 \pm 0.14)$ of GFB, indicating its greenness. The values of the $b^{*}$ coordinate were positive for both experimental GFs; however, GFB - in particular, its crust - was significantly more yellow than GFC (Table 3). The differences in the colours determined between the experimental GFs resulted from applied freeze-dried BLP, which was characterised with an intensive green hue $\left(a^{*}=-9.10 \pm 0.03 ; b^{*}=27.67 \pm 0.14\right)$. Among different techniques of dehydration, freeze-drying contributes to the preservation of colour and appearance and to minimise the degradation of thermolabile compounds, many of them responsible for the aromas and nutritional value of vegetables [44]. Many studies have demonstrated that the use of pigmented by-products of vegetable processing in bakery gluten-free products affected the colour parameters of the final product [12,13]. Therefore, it was expected that the green BLP applied in the present study would confer the colour characteristics of the supplemented GFB. Similarly, our previous study, where BLP was used to partly replace corn and potato starches in gluten-free sponge cake, resulted in a vivid-green end product [23]. However, in the confectionery product, the vividly green colour of the BLP-supplemented sponge cake was maintained mainly due to the high presence of sugar, while in GFB, since the content of sugar was much lower, a more brownish product was obtained.

\subsection{Textural Properties of Fresh and Stored Experimental Gluten-Free Bread}

The texture profile of crumb of fresh (two hours after baking) and stored ( 24 and $72 \mathrm{~h}$ ) experimental GFs is presented in Table 4. Fresh GFC and GFB were similarly soft (13.21 and 
$13.80 \mathrm{~N}$, respectively); however, fresh GFB was significantly $(p<0.05)$ springier and more cohesive than GFC. Besides, the chewiness of the GFB was over $50 \%$ higher compared with the GFC (Table 4). The chewiness informs about the time required to mastication a piece of food before it is swallowed. The incorporation of BLP into the gluten-free formulation prolonged the chewing time for the GFB crumb.

Table 4. Textural properties of fresh and stored experimental gluten-free bread.

\begin{tabular}{|c|c|c|c|}
\hline & GFC & GFB & $p$-Value \\
\hline \multicolumn{4}{|l|}{ Hardness (N) } \\
\hline Fresh & $13.21^{\mathrm{aC}} \pm 1.22$ & $13.80^{\mathrm{aC}} \pm 0.07$ & 0.4905 \\
\hline Stored $24 \mathrm{~h}$ & $29.53^{\mathrm{aB}} \pm 4.67$ & $33.16^{\mathrm{aB}} \pm 4.63$ & 0.3932 \\
\hline Stored $72 \mathrm{~h}$ & $45.78^{\mathrm{aA}} \pm 2.55$ & $42.86^{\mathrm{aA}} \pm 4.67$ & 0.2427 \\
\hline \multicolumn{4}{|l|}{ Springiness } \\
\hline Fresh & $0.93^{\mathrm{bA}} \pm 0.02$ & $0.99^{\mathrm{aA}} \pm 0.01$ & 0.0196 \\
\hline Stored $24 \mathrm{~h}$ & $0.90^{\mathrm{aA}} \pm 0.08$ & $0.92^{\mathrm{aB}} \pm 0.03$ & 0.7167 \\
\hline Stored $72 \mathrm{~h}$ & $0.83^{\mathrm{aA}} \pm 0.01$ & $0.89^{\mathrm{aC}} \pm 0.03$ & 0.0620 \\
\hline \multicolumn{4}{|l|}{ Cohesiveness } \\
\hline Fresh & $0.55^{\mathrm{bA}} \pm 0.07$ & $0.77^{\mathrm{aA}} \pm 0.02$ & 0.0249 \\
\hline Stored $24 \mathrm{~h}$ & $0.34^{\mathrm{aB}} \pm 0.11$ & $0.44^{\mathrm{aB}} \pm 0.03$ & 0.2523 \\
\hline Stored $72 \mathrm{~h}$ & $0.28^{\mathrm{aC}} \pm 0.01$ & $0.30^{\mathrm{aC}} \pm 0.01$ & 0.0705 \\
\hline \multicolumn{4}{|l|}{ Chewiness } \\
\hline Fresh & $6.73^{\mathrm{bB}} \pm 1.53$ & $10.45^{\mathrm{aA}} \pm 0.21$ & 0.0496 \\
\hline Stored $24 \mathrm{~h}$ & $8.88^{\mathrm{aB}} \pm 2.09$ & $13.51^{\mathrm{aA}} \pm 2.53$ & 0.0733 \\
\hline Stored $72 \mathrm{~h}$ & $10.77^{\mathrm{aA}} \pm 0.91$ & $11.51^{\mathrm{aA}} \pm 1.10$ & 0.4217 \\
\hline \multicolumn{4}{|l|}{ Resilience } \\
\hline Fresh & $0.31^{\mathrm{aA}} \pm 0.08$ & $0.50^{\mathrm{aA}} \pm 0.01$ & 0.0523 \\
\hline Stored $24 \mathrm{~h}$ & $0.16^{\mathrm{aB}} \pm 0.07$ & $0.24^{\mathrm{aB}} \pm 0.01$ & 0.1841 \\
\hline Stored $72 \mathrm{~h}$ & $0.12^{\mathrm{aC}} \pm 0.02$ & $0.13^{\mathrm{aC}} \pm 0.01$ & 0.4961 \\
\hline
\end{tabular}

In general, the storage influenced negatively the texture properties of GFs, independently of the BLP (Table 4). After $24 \mathrm{~h}$, the crumb of experimental GFs was more than two-time harder in comparison with the fresh crumbs. Longer storage $(72 \mathrm{~h})$ resulted in a further significant $(p<0.05)$ increase in the hardness of the GFC and GFB. Moreover, both stored GFs were significantly less cohesive, and their resilience was lower than in the case of the fresh samples (Table 4). The application of BLP in the gluten-free formulation caused a significant reduction of crumb springiness; thus, the GFB became very crumbly. However, in comparison with fresh GFB, the chewiness of stored crumb did not change meaningfully, contrary to the GFC stored for $72 \mathrm{~h}$ (Table 4). Ranawana et al. investigated the effect of the addition of freeze-dried vegetables (carrot, tomato, beetroot, and broccoli) on the storage properties of wheat bread with [45] and without oil [33]. The authors indicated that, among analysed vegetable breads, the broccoli bread was significantly $(p<0.05)$ harder compared to the control wheat bread both on the day of baking and during storage. However, the deterioration in texture attributes was more pronounced in the oil-free wheat bread [33]. Typically, a GF is characterised by a compact crumb with low cohesiveness and elasticity and, thus, high brittleness [46]. The textural characteristics of GF are strongly influenced by the ingredients used. Thus, if gluten is absent, the improvers (hydrocolloids, gums, and enzymes) become an obligatory element mimicking its functions [47,48], yielding a GF of satisfactory technological quality. Among them, fat-mimetic ingredients could be considered for improving texture, sensory characteristics, and shelf-life of baked products [49]. 


\subsection{Antioxidant Capacity of Experimental Gluten-Free Bread}

The results of the antioxidant capacity of the BLP and experimental GFs are presented in Table 5. The GFC was characterised by a relatively low antioxidant activity evaluated using all assays. Contrary, the BLP was found as a good source of TFC, consequently exerting a high antioxidant capacity. Freeze-drying, which was used to prepare BLP, is a well-known method that allows preserving the nutritional value of the starting material, including bioactive compounds [25]. Therefore, as expected, the fortification of GF with BLP significantly $(p<0.05)$ increased the antioxidant potential of experimental GFB. Among broccoli parts, leaf tissue had the highest TFC and antioxidant activity (DPPH), compared with florets and stems [19]. ABTS, DPPH, and PCL-ACW assays are associated with the activity of hydrophilic compounds like polyphenols, which have confirmation in TFC. On the other hand, the PCL-ACL assay informs about the activity of lipophilic compounds, like fat-soluble vitamins and carotenoids. The results obtained by Ranawana et al. [33,45] indicated that freeze-dried broccoli significantly increased the vitamin $\mathrm{E}(\alpha$ - and $\gamma$-tocopherols) content of broccoli breads compared with the wheat bread. Moreover, the authors showed that broccoli bread contained the $\beta$-carotene and lutein that are characterised by a strong antioxidant activity. BLP was characterised by very high PCL-ACL activity, and consequently, this assay was the highest among all analysed in GF, suggesting that BLP can be a good source of lipophilic compounds, as similarly suggested by other authors [50]. However, it was not analysed in this study and requires further investigation.

Table 5. Antioxidant capacity of experimental gluten-free bread.

\begin{tabular}{ccccc}
\hline & BLP & GFC & GFB & $p$ Value \\
\hline TFC $(\mathrm{mg} \mathrm{GAE} / \mathrm{g} \mathrm{dm})$ & $14.42 \pm 0.18$ & $0.64^{\mathrm{b}} \pm 0.04$ & $1.25^{\mathrm{a}} \pm 0.05$ & 0.001 \\
ACW $(\mu \mathrm{mol} / \mathrm{g} \mathrm{dm})$ & $3.29 \pm 0.10$ & $0.03^{\mathrm{b}} \pm 0.01$ & $1.64^{\mathrm{a}} \pm 0.08$ & 0.007 \\
ACL $(\mu \mathrm{mol} / \mathrm{g} \mathrm{dm})$ & $1191.25 \pm 64.37$ & $1.05^{\mathrm{b}} \pm 0.04$ & $106.97^{\mathrm{a}} \pm 0.87$ & $<0.001$ \\
ABTS $(\mu \mathrm{mol} \mathrm{TE} / \mathrm{g} \mathrm{dm})$ & $34.33 \pm 0.29$ & $0.13^{\mathrm{b}} \pm 0.01$ & $1.77^{\mathrm{a}} \pm 0.06$ & 0.003 \\
DPPH $(\mu \mathrm{mol} \mathrm{TE} / \mathrm{g} \mathrm{dm})$ & $34.11 \pm 0.29$ & $0.27^{\mathrm{b}} \pm 0.03$ & $0.95^{\mathrm{a}} \pm 0.05$ & 0.001 \\
\hline
\end{tabular}

GFC—Control gluten-free bread, GFB—Gluten-free bread enriched with broccoli leaf powder, BLP—Broccoli leaf powder, TFC—Total phenolic content, GAE—gallic acid equivalents, ACW-Antioxidative capacities of water-soluble compounds, ACL-Antioxidative capacities of lipid-soluble compounds, ABTS-2,2'-azino-bis(3ethylbenzothiazoline-6-sulfonic acid) $\left(\mathrm{ABTS}^{+}{ }^{+}\right.$) radical cation-based assays, DPPT-2-diphenyl-picryl-hydrazyl (DPPH) radical scavenging assay, and TE-Trolox Equivalents. Within each column, and for each factor, values with the same letter do not differ significantly $(p<0.05)$ when subjected to the unpaired $t$-test with Weich's correction.

A similar finding of increased antioxidant capacity after BLP incorporation was obtained in our previous study with BLP-fortified mini sponge cakes [24]. Moreover, the high antioxidant capacity of broccoli and its by-products was repeatedly reported in the literature [21,51]. Lefarga et al. indicated that wheat-based bread fortified with broccoli by-products was characterised by significantly increased TFC and antioxidant capacity in comparison to control bread without scarifying the sensory quality [21]. Interestingly, the authors reported that the TFC and antioxidant capacity increased after in vitro digestion, suggesting that the health-promoting potential of products fortified with broccoli by-products is even higher. Since the nutritional quality of GFs is relatively low, several successful attempts were performed aiming to improve the nutraceutical potential of these products, also including the vegetable by-products [12,52]. Our study also confirmed that underestimated by-products of broccoli processing can be a valuable additive to GF improving its nutritional and functional quality.

\subsection{Anti-AGEs Activity of Experimental Gluten-Free Bread}

The presence of phenolic compounds, besides the improvement of antioxidant potential, can contribute also to other bioactive activities. The advanced glycation end-products (AGEs) are formed continuously in the human body, the intensity of AGEs formation is increased by hyperglycemia and oxidative stress status [53]. Moreover, research has shown 
that dietary AGEs are important contributors to the pool of AGEs formed in the human body [54]. Hence, the challenge is to evaluate food products with natural inhibitors of the AGEs formation. The AGEs inhibitory activity was monitored in two model systems of BSA-MGO and BSA-glucose and presented in Figure 2. We found that extracts of BLP had high activity against the AGE formations (83.53\%) in the BSA-MGO study, almost the same as the reference material of aminoguanidine $(84.03 \%)$. The obtained data were in agreement with Sotokawauchi et al. [55], who noted the positive effect of broccoli sprouts decreased in the AGE formation. Additionally, a high effectiveness against AGE formation was noted in GFs after the addition of BLP (77.60\%) in comparison to the control $(67.47 \%)$. Therefore, the incorporation of BLP resulted in 1.15 times higher anti-AGE activity of the designed gluten-free product. In this study, we also observed that BLP showed a strong antiglycative effect $(p<0.05)$ in a BSA-glucose system, as is demonstrated in Figure 2. Similarly, in this model, the anti-AGE activity of BLP was high and accounted for $82.37 \%$. No significant difference was observed between samples of GFC and GFB, reaching 49.97 and $49.20 \%$, respectively.

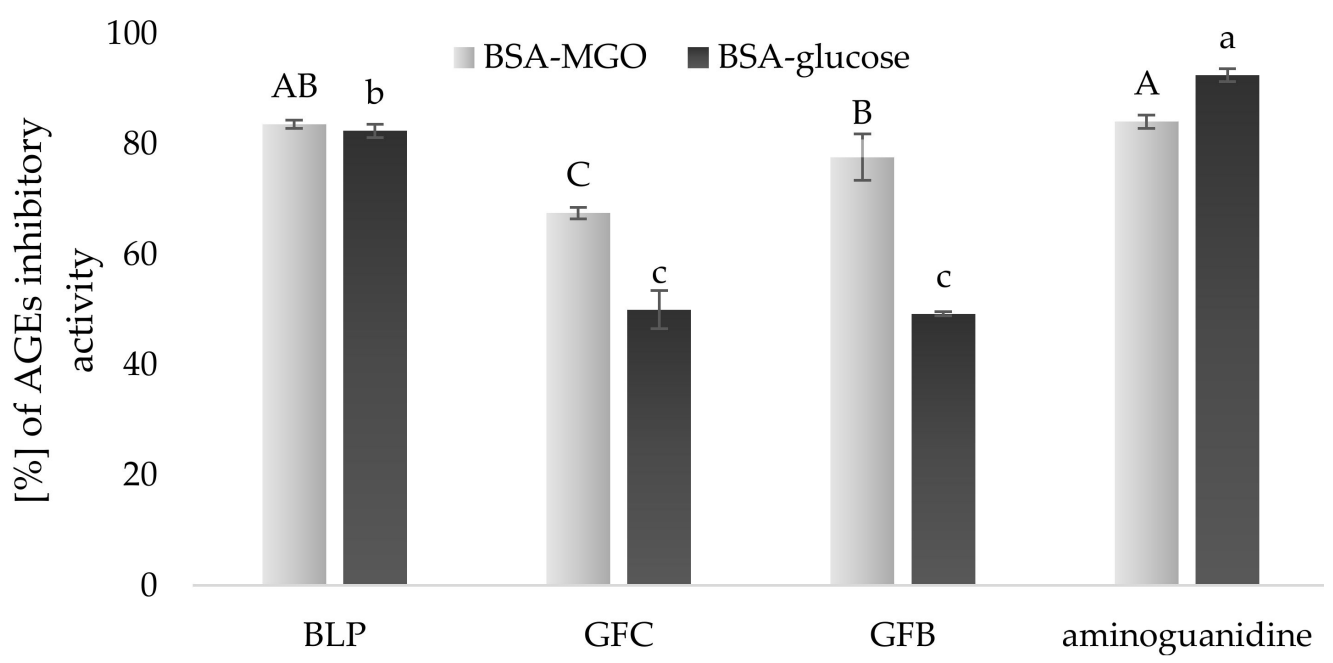

Figure 2. Results of anti- advanced glycation end-products (AGE) activity in models of bovine serum albumin-methylglyoxal (BSA-MGO) and BSA-glucose in samples of broccoli leaf powder (BLP), control gluten-free bread (GFC), and gluten-free bread enriched with broccoli leaf powder (GFB). The results are presented as the mean $\pm \mathrm{SD}(N=3)$. Bars with different letters denote significant differences $(p<0.05)$ when subjected to Tukey's test.

The results obtained in this study are in agreement with other studies utilising byproducts in bread formulation to improve the anti-AGE activity. The study of Peng et al. [56] showed that the incorporation of grape seeds can reduce the level of $\mathrm{N} \varepsilon$ (carboxymethyl)lysine (CML), a common advanced glycation end-product in bread. Another solution to reduce the AGEs in bread can be the application of gluten-free flour with a higher content of bioactive compounds. The study of Szawara-Nowak et al. [32] showed that buckwheat bread has higher inhibitory effects against the formation of AGEs than the control one.

Furthermore, a strong correlation was demonstrated between BSA-MGO and ACW and ACL ( $r=0.988$ and 0.829), whereas lower correlation coefficients were calculated for BSA-MGO vs. ABTS ( $r=0.808)$, BSA-MGO vs. DPPH $(r=0.793)$, and BSA-MGO vs. TPC $(r=0.806)$ (Table 6). A higher positive correlation was obtained between BSA-glucose and the antioxidant activity measured by ACL, ABTS, DPPH, and $r=0.995,0.998$, and 0.999, respectively, BSA-glucose, and TPC, $\mathrm{r}=0.998(p<0.05)$. A similar finding was reported by Szawara-Nowak et al. [32], who found a strong association between anti-AGE activity and TFC. Therefore, it seems that the BSA-glucose model could be a more suitable system to detect AGEs inhibitory activity of bakery products with broccoli leaves, because of high 
correlation coefficients between BSA-glucose and TPC values and the antioxidant activity measured by DPPH, ABTS, and ACW.

Table 6. Correlation coefficients for bovine serum albumin-methylglyoxal (BSA-MGO), BSA-glucose and antioxidant activity, and total phenolic content (TPC) relationship.

\begin{tabular}{ccc}
\hline & BSA-MGO & BSA-Glucose \\
\hline ACW & 0.988 & 0.859 \\
ACL & 0.829 & 0.995 \\
ABTS & 0.808 & 0.998 \\
DPPH & 0.793 & 0.999 \\
TPC & 0.806 & 0.998
\end{tabular}

ACW-Antioxidative capacities of water-soluble compounds, ACL-Antioxidative capacities of lipid-soluble compounds, ABTS-2,2'-azino-bis(3-ethylbenzothiazoline-6-sulfonic acid) (ABTS-+) radical cation-based assays, DPPT-2-diphenyl-picryl-hydrazyl (DPPH) radical scavenging assay, and TE-Trolox Equivalents.

\section{Conclusions}

The present study investigated the suitability and functionality of BLP as a GF component based on an analysis of the nutritional, technological, and functional properties of the developed product. Based on the results obtained, it can be noticed that BLP can be successfully used as an additive in gluten-free bakery products. It improved the nutritional value and the technological properties of the obtained bread. In particular, the specific volume and the bake loss of GFB have been significantly improved, compared to GFC. Additionally, the crumb of fresh GFB was as soft as of the GFC, although the inclusion of BLP resulted in the deterioration of the other textural parameters. However, what needs to be emphasised is that BLP improved the antioxidant potential and inhibitory activity against the AGE formations of GFB. In conclusion, the obtained added-value baked product could provide health-promoting benefits for subjects on a gluten-free diet; however, to validate this concept and verify the positive health effects of GFB, human intervention studies are needed.

Author Contributions: Conceptualisation, U.K.-K. and N.D.; methodology, U.K.-K., N.D., and M.S.; formal analysis, U.K.-K.; investigation, U.K.-K., N.D., N.B., K.Š., M.S., and T.J.; resources, U.K.-K.; writing—original draft preparation, U.K.-K.; writing—review and editing, U.K.-K., N.D., and M.S.; visualisation, U.K.-K.; and supervision, U.K.-K. All authors have read and agreed to the published version of the manuscript.

Funding: The study was financed from the research funds of the Institute of Animal Reproduction and Food Research of the Polish Academy of Sciences.

Acknowledgments: K.Š. is the EIT Food RIS Fellowship holder. Authors thank Fruit and Vegetables Warehouse GEMIX (Olsztyn, Poland) for donating broccoli leaves used in this work.

Conflicts of Interest: The authors declare no conflict of interest.

\section{References}

1. Conte, P.; Fadda, C.; Piga, A.; Collar, C. Techno-functional and nutritional performance of commercial breads available in Europe. Food Sci. Technol. Int. 2016, 22, 621-633. [CrossRef] [PubMed]

2. Cabanillas, B. Gluten-related disorders: Celiac disease, wheat allergy, and nonceliac gluten sensitivity. Crit. Rev. Food Sci. Nutr. 2020, 60, 2606-2621. [CrossRef]

3. Matos, M.E.; Rosell, C.M. Understanding gluten-free dough for reaching breads with physical quality and nutritional balance. $J$. Sci. Food Agric. 2014, 95, 653-661. [CrossRef] [PubMed]

4. Ronda, F.; Pérez-Quirce, S.; Villanueva, M. Rheological Properties of Gluten-Free Bread Doughs: Relationship with Bread Quality. In Advances in Food Rheology and Its Applications; Woodhead Publishing: Cambridge, UK, 2016; pp. 297-334.

5. Zannini, E.; Jones, J.M.; Renzetti, S.; Arendt, E.K. Functional Replacements for Gluten. Annu. Rev. Food Sci. Technol. 2012, 3, 227-245. [CrossRef] [PubMed]

6. Conte, P.; Fadda, C.; Drabińska, N.; Krupa-Kozak, U. Technological and nutritional challenges, and novelty in gluten-free breadmaking: A review. Pol. J. Food Nutr. Sci. 2019, 69. [CrossRef] 
7. Sedlar, T.; Čakarević, J.; Tomić, J.; Popović, L. Vegetable By-Products as New Sources of Functional Proteins. Plant Foods Hum. Nutr. 2020, 76, 31-36. [CrossRef]

8. Hooper, L.; Cassidy, A. A review of the health care potential of bioactive compounds. J. Sci. Food Agric. 2006, 86, 1805-1813. [CrossRef]

9. Shapiro, T.A.; Fahey, J.W.; Dinkova-Kostova, A.T.; Holtzclaw, W.D.; Stephenson, K.K.; Wade, K.L.; Ye, L.; Talalay, P. Safety, Tolerance, and Metabolism of Broccoli Sprout Glucosinolates and Isothiocyanates: A Clinical Phase I Study. Nutr. Cancer 2006, 55, 53-62. [CrossRef]

10. Koch, W. Dietary Polyphenols-Important Non-Nutrients in the Prevention of Chronic Noncommunicable Diseases. A Systematic Review. Nutrients 2019, 11, 1039. [CrossRef]

11. Korus, J.; Juszczak, L.; Ziobro, R.; Witczak, M.; Grzelak, K.; Sójka, M. Defatted strawberry and blackcurrant seeds as functional ingredients of gluten-free bread. J. Texture Stud. 2012, 43, 29-39. [CrossRef]

12. Majzoobi, M.; Poor, Z.V.; Jamalian, J.; Farahnaky, A. Improvement of the quality of gluten-free sponge cake using different levels and particle sizes of carrot pomace powder. Int. J. Food Sci. Technol. 2016, 51, 1369-1377. [CrossRef]

13. Talens, C.; Álvarez-Sabatel, S.; Rios, Y.; Rodríguez, R. Effect of a new microwave-dried orange fibre ingredient vs. a commercial citrus fibre on texture and sensory properties of gluten-free muffins. Innov. Food Sci. Emerg. Technol. 2017, 44, 83-88. [CrossRef]

14. Littardi, P.; Rinaldi, M.; Grimaldi, M.; Cavazza, A.; Chiavaro, E. Effect of Addition of Green Coffee Parchment on Structural, Qualitative and Chemical Properties of Gluten-Free Bread. Foods 2021, 10, 5. [CrossRef] [PubMed]

15. Herr, I.; Büchler, M.W. Dietary constituents of broccoli and other cruciferous vegetables: Implications for prevention and therapy of cancer. Cancer Treat. Rev. 2010, 36, 377-383. [CrossRef]

16. Gawlik-Dziki, U.; Świeca, M.; Dziki, D.; Sęczyk, Ł.; Złotek, U.; Różyło, R.; Kaszuba, K.; Ryszawy, D.; Czyż, J. Anticancer and Antioxidant Activity of Bread Enriched with Broccoli Sprouts. BioMed Res. Int. 2014, 2014, 608053. [CrossRef]

17. Nuñez-Gómez, V.; Baenas, N.; Navarro-González, I.; García-Alonso, J.; Moreno, D.A.; González-Barrio, R.; Periago-Castón, M.J. Seasonal Variation of Health-Promoting Bioactives in Broccoli and Methyl-Jasmonate Pre-Harvest Treatments to Enhance Their Contents. Foods 2020, 9, 1371. [CrossRef]

18. Domínguez-Perles, R.; Martínez-Ballesta, M.C.; Carvajal, M.; García-Viguera, C.; Moreno, D.A. Broccoli-derived by-products-A promising source of bioactive ingredients. J. Food Sci. 2010, 75, C383-C392. [CrossRef] [PubMed]

19. Liu, M.; Zhang, L.; Ser, S.L.; Cumming, J.R.; Ku, K.M. Comparative Phytonutrient Analysis of Broccoli By-Products: The Potentials for Broccoli By-Product Utilization. Molecules 2018, 23, 900. [CrossRef]

20. Borja-Martínez, M.; Lozano-Sánchez, J.; Borrás-Linares, I.; Pedreño, M.A.; Sabater-Jara, A.B. Revalorization of Broccoli ByProducts for Cosmetic Uses Using Supercritical Fluid Extraction. Antioxidants 2020, 9, 1195. [CrossRef]

21. Lafarga, T.; Gallagher, E.; Bademunt, A.; Viñas, I.; Bobo, G.; Villaró, S.; Aguiló-Aguayo, I. Bioaccessibility, physicochemical, sensorial, and nutritional characteristics of bread containing broccoli co-products. J. Food Process. Preserv. 2019,43 , e13861. [CrossRef]

22. Melini, V.; Melini, F.; Luziatelli, F.; Ruzzi, M. Functional Ingredients from Agri-Food Waste: Effect of Inclusion Thereof on Phenolic Compound Content and Bioaccessibility in Bakery Products. Antioxidants 2020, 9, 1216. [CrossRef]

23. Krupa-Kozak, U.; Drabińska, N.; Rosell, C.M.; Fadda, C.; Anders, A.; Jeliński, T.; Ostaszyk, A. Broccoli leaf powder as an attractive by-product ingredient: Effect on batter behaviour, technological properties and sensory quality of gluten-free mini sponge cake. Int. J. Food Sci. Technol. 2019, 54, 1121-1129. [CrossRef]

24. Drabińska, N.; Ciska, E.; Szmatowicz, B.; Krupa-Kozak, U. Broccoli by-products improve the nutraceutical potential of gluten-free mini sponge cakes. Food Chem. 2018, 267, 170-177. [CrossRef]

25. Xu, Y.; Xiao, Y.; Lagnika, C.; Li, D.; Liu, C.; Jiang, N.; Song, J.; Zhang, M. A comparative evaluation of nutritional properties, antioxidant capacity and physical characteristics of cabbage (Brassica oleracea var. Capitate var L.) subjected to different drying methods. Food Chem. 2020, 309, 124935. [CrossRef] [PubMed]

26. Krupa-Kozak, U.; Troszyńska, A.; Bączek, N.; Soral-Śmietana, M. Effect of organic calcium supplements on the technological characteristic and sensory properties of gluten-free bread. Eur. Food Res. Technol. 2011, 232, 497-508. [CrossRef]

27. AOAC. Official Methods of Analysis of AOAC International, 18th ed.; Current through Revision 4; Association of Official Analytical Chemists: Gaithersburg, MD, USA, 2011; pp. 54, 57-58.

28. FAO. Food Energy - Methods of Analysis and Conversion Factors. Report of a Technical Workshop, Rome, Italy, 3-6 December 2002; FAO Food and Nutrition Paper 77; Food and Agriculture Organization of The United Nations: Rome, Italy, 2003. Available online: http:/ / www.fao.org/3/y5022e/y5022e00.htm\#Contents (accessed on 9 April 2021).

29. Bourne, M.C.; Kenny, J.F.; Barnard, J. Computer-Assisted Readout Of Data From Texture Profile Analysis Curves1. J. Texture Stud. 1978, 9, 481-494. [CrossRef]

30. Horszwald, A.; Andlauer, W. Characterisation of bioactive compounds in berry juices by traditional photometric and modern microplate methods. J. Berry Res. 2011, 1, 189-199. [CrossRef]

31. Zieliński, H.; Zielińska, D.; Kostyra, H. Antioxidant capacity of a new crispy type food products determined by updated analytical strategies. Food Chem. 2012, 130, 1098-1104. [CrossRef]

32. Szawara-Nowak, D.; Koutsidis, G.; Wiczkowski, W.; Zieliński, H. Evaluation of the in vitro inhibitory effects of buckwheat enhanced wheat bread extracts on the formation of advanced glycation end-products (AGEs). Lebensm. Wiss. Technol. 2014, 58, 327-334. [CrossRef] 
33. Ranawana, V.; Campbell, F.; Bestwick, C.; Nicol, P.; Milne, L.; Duthie, G.; Raikos, V. Breads Fortified with Freeze-Dried Vegetables: Quality and Nutritional Attributes. Part II: Breads Not Containing Oil as an Ingredient. Foods 2016, 5, 62. [CrossRef]

34. Betoret, E.; Rosell, C.M. Effect of particle size on functional properties of Brassica napobrassica leaves powder. Starch interactions and processing impact. Food Chem. X 2020, 8, 100106. [CrossRef]

35. Vidrih, R.; Filip, S.; Hribar, J. Content of higher fatty acids in green vegetables. Czech J. Food Sci. 2009, 27, 125-129. [CrossRef]

36. Arnáiz, E.; Bernal, J.; Martín, M.T.; García-Viguera, C.; Bernal, J.L.; Toribio, L. Supercritical fluid extraction of lipids from broccoli leaves. Eur. J. Lipid Sci. Technol. 2011, 113, 479-486. [CrossRef]

37. Ding, S.; Peng, B.; Li, Y.; Yang, J. Evaluation of specific volume, texture, thermal features, water mobility, and inhibitory effect of staling in wheat bread affected by maltitol. Food Chem. 2019, 283, 123-130. [CrossRef] [PubMed]

38. Wang, J.; Rosell, C.M.; Benedito de Barber, C. Effect of the addition of different fibres on wheat dough performance and bread quality. Food Chem. 2002, 79, 221-226. [CrossRef]

39. Miranda-Ramos, K.C.; Haros, C.M. Combined Effect of Chia, Quinoa and Amaranth Incorporation on the Physico-Chemical, Nutritional and Functional Quality of Fresh Bread. Foods 2020, 9, 1859. [CrossRef] [PubMed]

40. Fratelli, C.; Muniz, D.G.; Santos, F.G.; Capriles, V.D. Modelling the effects of psyllium and water in gluten-free bread: An approach to improve the bread quality and glycemic response. J. Funct. Foods 2018, 42, 339-345. [CrossRef]

41. Elgeti, D.; Nordlohne, S.D.; Föste, M.; Besl, M.; Linden, M.H.; Heinz, V.; Jekle, M.; Becker, T. Volume and texture improvement of gluten-free bread using quinoa white flour. J. Cereal Sci. 2014, 59, 41-47. [CrossRef]

42. Hu, S.H.; Wang, J.C.; Kung, H.F.; Wang, J.T.; Lee, W.L.; Yang, Y.H. Antimicrobial Effect of Extracts of Cruciferous Vegetables. Kaohsiung J. Med. Sci. 2004, 20, 591-599. [CrossRef]

43. Conte, P.; Del Caro, A.; Balestra, F.; Piga, A.; Fadda, C. Bee pollen as a functional ingredient in gluten-free bread: A physicalchemical, technological and sensory approach. Lebensm. Wiss. Technol. 2018, 90, 1-7. [CrossRef]

44. Karam, M.C.; Petit, J.; Zimmer, D.; Baudelaire Djantou, E.; Scher, J. Effects of drying and grinding in production of fruit and vegetable powders: A review. J. Food Eng. 2016, 188, 32-49. [CrossRef]

45. Ranawana, V.; Raikos, V.; Campbell, F.; Bestwick, C.; Nicol, P.; Milne, L.; Duthie, G. Breads Fortified with Freeze-Dried Vegetables: Quality and Nutritional Attributes. Part 1: Breads Containing Oil as an Ingredient. Foods 2016, 5, 19. [CrossRef] [PubMed]

46. Gallagher, E.; Gormley, T.R.; Arendt, E.K. Crust and crumb characteristics of gluten free breads. J. Food Eng. 2003, 56, 153-161. [CrossRef]

47. Belorio, M.; Gómez, M. Effect of Hydration on Gluten-Free Breads Made with Hydroxypropyl Methylcellulose in Comparison with Psyllium and Xanthan Gum. Foods 2020, 9, 1548. [CrossRef] [PubMed]

48. Sarabhai, S.; Tamilselvan, T.; Prabhasankar, P. Role of enzymes for improvement in gluten-free foxtail millet bread: It's effect on quality, textural, rheological and pasting properties. Lebensm. Wiss. Technol. 2021, 137, 110365. [CrossRef]

49. Gray, J.A.; Bemiller, J.N. Bread staling: Molecular basis and control. Compr. Rev. Food Sci. Food Saf. 2003, 2, 1-21. [CrossRef] [PubMed]

50. Ramirez, D.; Abellán-Victorio, A.; Beretta, V.; Camargo, A.; Moreno, D.A. Functional Ingredients from Brassicaceae Species: Overview and Perspectives. Int. J. Mol. Sci. 2020, 21, 1998. [CrossRef] [PubMed]

51. Soengas, P.; Cartea, M.E.; Francisco, M.; Sotelo, T.; Velasco, P. New insights into antioxidant activity of Brassica crops. Food Chem. 2012, 134, 725-733. [CrossRef] [PubMed]

52. Ostermann-Porcel, M.V.; Quiroga-Panelo, N.; Rinaldoni, A.N.; Campderrós, M.E. Incorporation of Okara into Gluten-Free Cookies with High Quality and Nutritional Value. J. Food Qual. 2017, 2017, 4071585. [CrossRef]

53. Ames, J.M. Evidence against dietary advanced glycation endproducts being a risk to human health. Mol. Nutr. Food Res. 2007, 51, 1085-1090. [CrossRef] [PubMed]

54. Uribarri, J.; del Castillo, M.D.; de la Maza, M.P.; Filip, R.; Gugliucci, A.; Luevano-Contreras, C.; Macías-Cervantes, M.H.; Markowicz Bastos, D.H.; Medrano, A.; Menini, T.; et al. Dietary advanced glycation end products and their role in health and disease. Adv. Nutr. 2015, 6, 461-473. [CrossRef] [PubMed]

55. Sotokawauchi, A.; Ishibashi, Y.; Matsui, T.; Yamagishi, S.I. Aqueous Extract of Glucoraphanin-Rich Broccoli Sprouts Inhibits Formation of Advanced Glycation End Products and Attenuates Inflammatory Reactions in Endothelial Cells. Evid. Based Complement. Altern. Med. 2018, 2018, 9823141. [CrossRef] [PubMed]

56. Peng, X.; Ma, J.; Cheng, K.W.; Jiang, Y.; Chen, F.; Wang, M. The effects of grape seed extract fortification on the antioxidant activity and quality attributes of bread. Food Chem. 2010, 119, 49-53. [CrossRef] 